\title{
Theory and practice
}

With the UK's 2008 Research Assessment Exercise looming, we make no apologies for publishing a further exploration of the nature of architectural research. In her paper (pp141-147), Jane Rendell makes a lucid and persuasive case that design is a complex interdisciplinary activity that sits uneasily within current definitions of research. For Rendell, architectural design, just as much as writing, can be practised as a form of criticism, a proposition that was explored at 'Critical Architecture', the recent conference at the Bartlett School in London (pp105-108).

It is difficult to imagine many projects that would better illustrate the potentially exploratory and critical nature of design, or more admirably fulfil arq's ambition to link practice and research, than the transformation of a severe Prussian school by Susanne Hofmann and her student group Baupiloten based in Berlin (pp114-127). Recalling that German expressionist tradition which Iain Boyd White so aptly described as the 'Architecture of Activism', the dream-world which has materialised in the school's severe corridors and staircases is so imaginatively conceived and skilfully made that it sets new standards for participatory practice.

Whilst the work of the Baupiloten contains criticism that is operative on many levels and made entirely through the medium of architectural form, Hofmann's account of the project is written as an unadorned narrative rather than a theoretical speculation. In Book 1 of his eponymous treatise, Vitruvius recommended architects to write in order to ensure, through their commentaries, the longevity of their buildings. The lack of surviving texts from the Classical world suggests that he had little more success in his time than we are having now in persuading busy practitioners to present and reflect on their work through these pages.

The hectic pace of contemporary practice offers an understandable explanation for practitioners' reluctance to write, but we suspect that there may also be a widespread concern that, in order to appear in a research journal, the commentary - as opposed to the building - must be made overtly 'theoretical'. If, as we believe, the design and making of innovative buildings is in itself a central form of architectural research, and potentially also of criticism, then it is vital for the health of both a journal such as arq, and of schools of architecture in increasingly research-oriented universities, that links with thoughtful practitioners are consolidated. Like many such, Günther Behnisch (pp109-113) is doubtful about the validity of envisaging architecture as a simplistic building out of verbal arguments, but like all architects of high ambition his work espouses a clear theoretical and critical position. We seek for these pages reflective, clearly-written accounts of the intentions, ideas and processes involved in the realisation of imaginative work. 